\title{
Joined supernumerary mandibular teeth in the premolar region: Report of a Hungarian archeological case
}

\author{
Gy. Szabó*, G. Kocsis S., E. Molnár \\ University of Szeged, Department of Anthropology, Szeged - Hungary, H-6701
}

ABSTRACT Supernumerary teeth are those that are additional to the normal complement. They may occur in any region of the dental arch and have been reported in both the primary and the permanent dentitions. The etiology of supernumerary teeth is still not clearly understood, but several theories have been suggested for their occurrence. The investigated material were the remains from the Bácsalmás-Óalmás burial site (from the 16th-17th centuries), where 472 skeletons were excavated from 1993 to 2003. For the purpose of this study, the dentitions of 164 adult individuals were examined. The examination was carried out using macromorphological methods, radiographic analysis and a dial caliper were applied. This paper describes a supernumerary tooth of an adult female skeleton. On the labial surface of the first mandibular premolar an extra tooth was observed.

Supernumerary teeth are those that are additional to the normal complement (Schulze, 1987). They may occur in any region of the dental arch with a particular predilection for the premaxilla (Primosch, 1981; Nasif et al., 1983). This location is followed in decreasing order of frequency by fourth molars or upper distal molars, maxillary paramolars and by lower premolars, upper lateral incisors, lower fourth molars, and lower central incisors. Upper premolars are exceptional, as are upper and lower canines and lower lateral incisors (Gay et al., 1999). Supernumerary teeth have been reported in both the primary and the permanent dentitions. Cases involving one or two supernumerary teeth most commonly involve the anterior maxilla (Stafne, 1932), followed by the mandibular premolar region (Nasif et al., 1983; Stafne, 1932).

The etiology of supernumerary teeth is still not clearly understood, but several theories have been suggested for their occurrence (Rajab and Hamdan, 2002). For developmental biologists, the phenomenon of supernumerary teeth raises interesting questions about the development and fate of the dental lamina. Also, the supernumerary teeth inspire questions about the actions and interactions of transcription factors and growth factors that coordinate morphogenesis, cell survival and programmed cell death. For clinicians faced with treating the dental complications that arise from the presence of supernumerary teeth, knowledge about the
Radiographic examination of the fused teeth indicated that the crown of the premolar had fused incompletely with the crown of the extra tooth. The position of the extra tooth could have been the result of gemination of the tooth germ or the elaboration of the buccal cingulum. The cranium of the examined individual showed some mongoloid morphologic features, too. Our presumption about the formation of the supernumerary tooth may have contributed to the theories of the occurrence of supernumeraries. The sporadic occurrence of this anomaly was reported in recent and archaeological skeletal collections. This study showed that multiple permanent dental formation was present in past Hungarian populations, representing a contribution to the history of dental anomalies. Dental Anthropology 2009;22(1):19-22.

basic mechanisms involved is essential.

Heredity may be a relevant etiological factor in the occurrence of supernumerary teeth (Rajab and Hamdan, 2002). Supernumeraries are more common in the relatives of affected children than in the general population (Garvey et al., 1999). The reported prevalence of supernumeraries in the general Caucasian population for the permanent dentition ranges from 0.1 to $3.8 \%$ (Rajab and Hamdan, 2002). Supernumerary teeth seem to be more common in Asian populations, with a frequency higher than 3\% being reported (Davis, 1987). Sexual dimorphism has been reported by most authors (Hurlen and Humerfelt, 1985; Mitchell, 1989) with males being affected more commonly.

The occurrence of this anomaly is also reported in archeological skeletal collections. Hillebrand (1908) found 14 supernumerary teeth during the paleostomatological investigation of 4,100 skulls. Schwerz (1916) described this anomaly in two out of 510 cases. The sporadic occurrence of supernumeraries in past populations was reported in several other studies

Correspondence to: Gyöngyi Szabó, H-6701 Szeged,

P.O. Box 660, Hungary

E-mail: szabo.gyongi@hotmail.com 


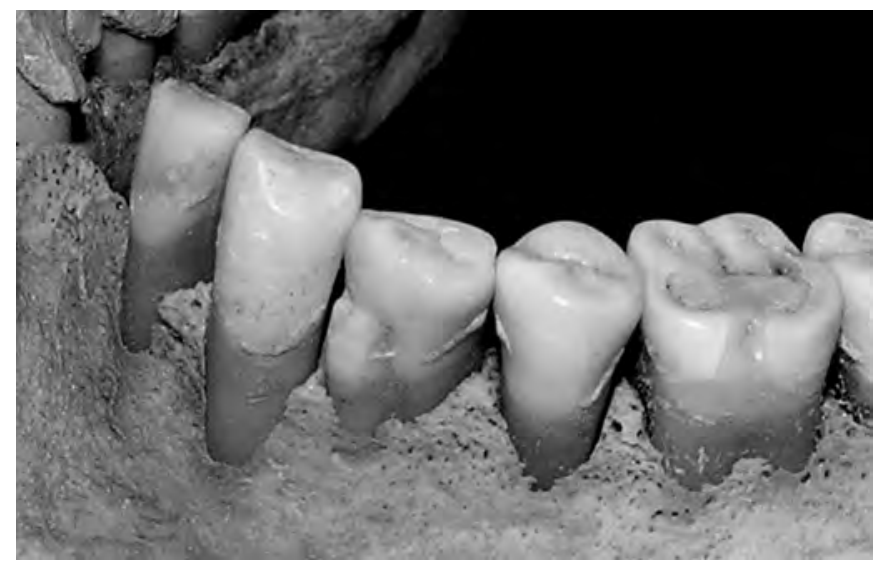

Fig. 1. Joined supernumerary tooth in the left premolar region of mandible.

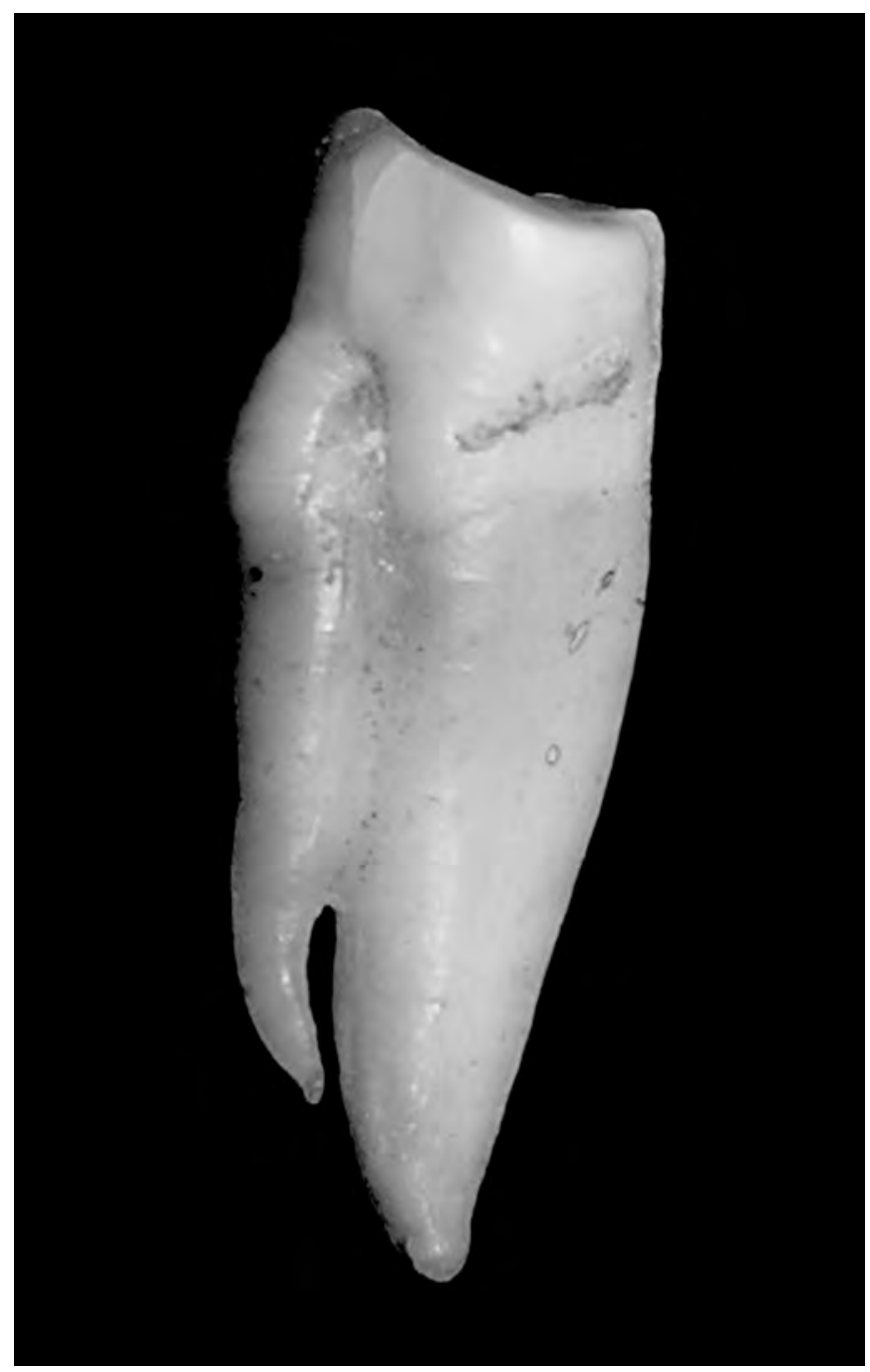

Fig. 2. Distal view of the double tooth formation. Lingual is to the right. collected by Kocsis (1993).

This report describes a rare developmental anomaly of a mandibular tooth of a young adult (25-30 yrs) female.

\section{MATERIALS AND METHODS}

The material for this report was the skeletal population of Bácsalmás-Óalmás burial site found in a sand pit, where 472 skeletons were excavated from 1993 to 2003. On the basis of the archeological and historical data, this group immigrated from the Balkan Peninsula to the southern part of Hungary in the sixteenth century. For the purpose of this study, the dentitions of 164 wellpreserved adult individuals (76 males, 75 females, 13 indeterminate) were examined. Altogether 2,693 teeth (with the exception of the third molars) were used for the investigation. The examination was carried out using macromorphological methods and radiographic analysis. A dial caliper was used for the metric analysis.

\section{RESULTS}

During the paleostomatological investigation, altered number of teeth was one of the examined anomalies. The present report is a case of hyperdontia. The lower left first premolar of the young adult female revealed double tooth formation. Only this one case of hyperdontia was found from among the 164 skulls in the skeletal series of Bácsalmás-Óalmás. Due to postmortem loss, the young adult female had no upper left incisors and the upper right central incisor was missing. Pitted hypoplasia on the incisors was seen. Mild periodontal atrophy was

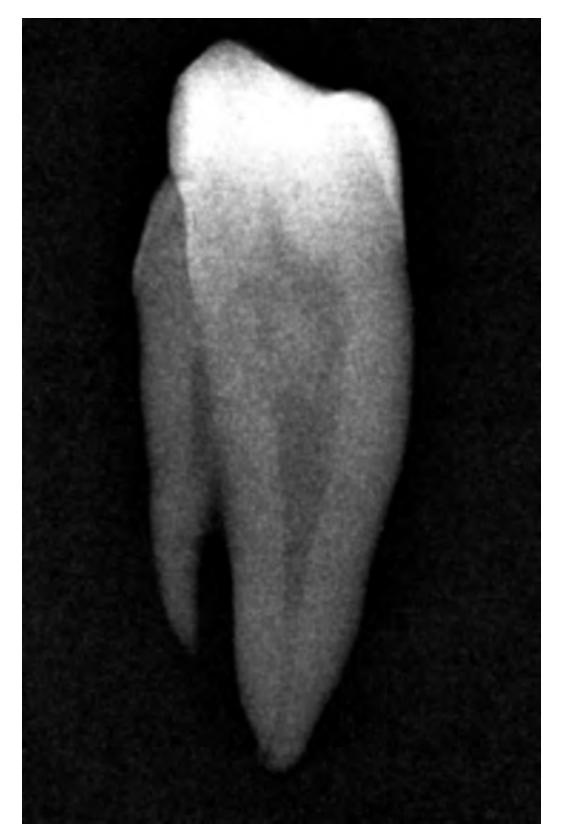

Fig. 3. Mesiodistal radiographic image of the double tooth formation. Lingual is to the right. 
evident on the whole dental arch.

On the labial surface of the mandibular first premolar, there is a supernumerary tooth, where the size was definitely smaller than the premolar (Fig. 1, 2 ). The double tooth displays a bifid crown with a welldefined groove that extends to the distal third of the root. The crown height was $3.64 \mathrm{~mm}$, while that of the premolar-proper was $8.14 \mathrm{~mm}$. The greatest mesiodistal dimension of the accessory crown was $3.22 \mathrm{~mm}$ and 7.28 $\mathrm{mm}$ for the first premolar. Root length was $10.62 \mathrm{~mm}$ and $14.32 \mathrm{~mm}$ for the premolar. No anomaly was observed in the right mandibular quadrant, so this represents a unilateral event.

The cranium showed some Mongoloid morphologic features, such as shallow canine fossa and shovel shaped upper incisors. The skeletal remains were well preserved. All of the teeth were found with the exception for the upper left canine, the upper left third molar and the upper right third molar. The status of their alveoli indicates postmortem loss. Different stages of dental caries occurred on the occlusal and mesial surfaces of molars. Caries superficialis were the most common, but a single case of caries penetrans was also observed, on the upper right first molar.

\section{DISCUSSION}

Supernumerary teeth may occur singly or in multiples in any region of the jaws in the same person. This study describes a unilateral supernumerary mandibular tooth of an adult female skeleton. Radiographic examination of the fused teeth indicated that the crown of the normal premolar had fused incompletely with the crown of the extra tooth. The fused teeth have two root canals and two partly separate roots. Communication between the pulp chambers of the teeth could be detected radiographically. The position of the extra tooth can be the result of gemination of the first premolar, which means that two morphological units were created by division of the tooth germ. The result is the incomplete formation of two teeth. According to Pindborg (1970), a true concretion develops during the formation of teeth and it is caused by the lack of space. But from another perspective the extra tooth can be the elaboration of the buccal cingulum of the premolar. In support of this concept, the crown is not fused completely and the roots are separated.

Regarding the etiology of this dental anomaly, Rajab and Hamdan (2002) considered heredity as an important etiological factor in the occurrence of supernumerary teeth. Heredity is not conclusive as no other supernumerary was found in this skeletal collection (164 skulls).

The fact that supernumerary teeth are more common in Mongoloid racial groups seems to be conclusive in this case because the investigated skull also shows Mongoloid characteristics.
Clinical complications related to double teeth include caries along the grooves dividing each other and periodontal atrophy, esthetics, and malocclusion (Silva and Silva, 2007). In extant groups, the majority of such teeth are asymptomatic, so endodontic treatment is unnecessary in most cases (Cetinbas et al., 2007).

The sporadic occurrence of supernumerary teeth is reported in recent (Hassan et al., 2006) and archeological (Sutton, 1985; Smith, 2004) skeletal collections. Kocsis (1993) investigated the permanent frontal teeth of 1,997 individuals originating from different archeological periods of Hungary. He found 23 supernumeraries with a highest frequency in the 10th century AD.

This case report shows that permanent dental formations in the premolar region were also present in the past populations of Hungary, representing a contribution to the history of dental anomalies.

\section{LITERATURE CITED}

Cetinbas T, Halil S, Akcam MO, Sari S, Cetiner S. 2007. Hemisection of a fused tooth. Oral Surg Oral Med Oral Path Oral Radiol Endod 104:120-124

Davis PJ. 1987. Hypodontia and hyperdontia of permanent teeth in Hong Kong school children. Community Dent Oral Epidemiol 15:218-220.

D'Souza RN, Klein OD. 2007. Unraveling the molecular mechanisms that lead to supernumerary teeth in mice and men: current concepts and novel approaches. Cells Tissues Organs 186:60-69.

Garvey MT, Berry HJ, Blake M. 1999. Supernumerary teeth-an overview of classification, diagnosis and management. J Can Dent Assoc 61:612-616

Gay C, Mateos M, España A, Gargallo J. 1999. Otras inclusiones dentarias: Mesiodens y otros dientes supernumerarios. Dientes temporales incluidos. In: Gay C, Berini L, editors. Cirugía Bucal. Madrid: Editorial Ergon, Madrid. p 511-550.

Hillebrand J. 1908. Újabb adatok az ember fogainak alaktanához. Budapest: Stephaneum.

Hurlen B, Humerfelt D. 1985. Characteristics of premaxillary hyperodontia: a radiographic study. Acta Odontol Scand 43:75-81.

Kocsis SG. 1993. Investigation of macromorphological developmental anomalies of permanent front teeth from different archaeological periods of Hungary. Thesis, JATE, Department of Anthropology, Szeged [in Hungarian].

Mitchell L. 1989. Supernumerary teeth. Dent Update 16:65-69.

Nasif MM, Ruffalo RC, Zullo T. 1983. Impacted supernumerary teeth: a survey of 50 cases. J Amer Dent Assoc 106:201-204.

Pindborg JJ. 1970. Pathology of the dental hard tissues. San Francisco: WB Saunders Company.

Primosch R. 1981 Anterior supernumerary teeth-assessment and surgical intervention in children. Pediatr 
Dent 3:204-215.

Rajab LD, Hamdan MAM. 2002. Supernumerary teeth: review of the literature and survey of 152 cases. Int Peadiatr Dent 12:244-254.

Schulze Ch. 1987. Anomalien und Mißbildungen der menschlichen Zähne. Quintessenz VOL 94-101.

Schwerz F. 1916. Morphologische Untersuchungen an Zähnen von Alamannen aus dem V. bis X. Jahrhundert. Arch Anthropol 15:1-43.

Silva AM, Silva AL. 2007. Unilateral fusion of two primary mandibular teeth: report of a Portuguese archeological case. Dental Anthropology 20:16-18.
Smith P. 2004. Middle bronze age II burials at Sasa, Upper Galilee (Tomb 1 and graves 37, 39). 'Atiqut 46:35-43.

Stafne EC. 1932. Supernumerary teeth. Dental Cosmos 74:653-659.

Sutton PR. 1985. Tooth eruption and migration theories: can they account for the presence of a 13,000-yearold mesiodens in the vault of the palate? Oral Surg Oral Med Oral Path Oral Radiol Endod 59:252-255.

\title{
Commentary: Supernumerary teeth
}

\author{
Edward F. Harris
}

\section{Department of Orthodontics and Department of Pediatric Dentistry, University of Tennessee, Memphis}

The case report by Gyongyi Szabó and colleagues (Dental Anthropology 2009;22(1):18-21) raises several interesting issues. A challenging aspect of examining teeth - which are the end-products of foregone cascades of developmental events - is that interpretations of the formative processes that produced the final form are conjectural, and there is no way to test assumptions. Experience and encountering repeated occurrences of a dental condition are helpful, but they are hardly infallible.

\section{Terminology}

A fundamental consideration raised by this case report is terminology. Specifically, what constitutes a supernumerary tooth? Or, for that matter, what is a tooth? I looked through a number of recent papers on hypo- and hyperdontia, and there is a striking absence of an operational definition of what a "tooth" is. Recognition of a tooth evidently is considered so obvious (or so difficult) that it doesn't warrant a definition. It seems that mineralized tissues (dentin, enamel) are an important criterion, but this is simply because most studies nowadays are radiographic surveys, so premineralized tissues are undetectable. However, dental histologists are quite comfortable that the premineralized structures seen in the bud, cap, and bell stages constitute a "tooth," so mineralization cannot be an essential feature.

Popular textbooks on dental anatomy (e.g., Zeisz and Nuckolls, 1949; Kraus et al., 1969; Ash, 1993) launch right into descriptions of the morphology of each tooth type, apparently supposing that a definition would be superfluous. The normally-occurring teeth (20 primary, 32 permanent) are all characterized by a

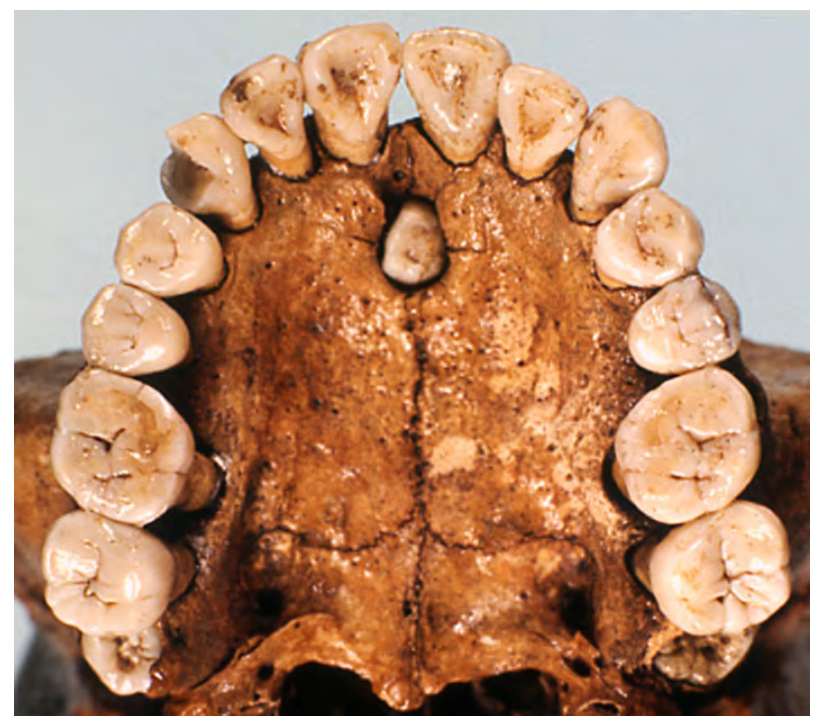

Fig. 4. A supernumerary tooth in the enlarged incisive foramen of a prehistoric American Indian. Ectopic teeth tend to be in the vicinity of the dental arches, but they may form or migrate elsewhere.

crown (enamel, dentin, pulp) and one or more roots (cementum, dentin, pulp), but it is not clear whether a dental element must have all of these features to achieve "toothness." Also, sizes of the crown and root do not seem to be important criteria. One might claim that teeth obviously are found in the two dental arches, but locality is not definitive given the extraordinary

*Correspondence to: Edward F. Harris, Department of Orthodontics, University of Tennessee, Memphis, TN 38163.

E-mail: eharris@utmem.edu 